214 Bousquet, Cambier, Morand...

[19] Welcomme R. L., Review of the present state of-knowledge of fish stocks and fisheries of African rivers. In Proc of-the-Int. Large-River Sympodium, ed. by Dodge D. P.,
Can. Spec-Pübl. Fish. Aquat. Sci. 106 (1989) pp. 515-532.-

\section{SIMULATING THE INTERACTION BETWEEN A SOCIETY AND A RENEWABLE RESOURCE}

F. BOUSQUET, C. CAMBIER and C. MULLON

Laboratoire d'Informatique Appliguée, ORSTOM, 70-74 route

d'Aulnay, 99143 Bondy Cedex, France

P. MORAND and J. QUENSIERE

Programme Delta Central du Niger, Centre ORSTOM, BP 2528, Bamako, Mali

\section{A. PAVÉ}

Laboratoire de Biométrie, Génttique et Biologie des populations, URA CNRS $n^{\circ} 249$, Université Claude Bernard - Lyon 1, $\$ 9$ Boulevard du 11 Novembre 1918 , F-69622 Villeurbanne Cedex, France

Received 11 May 1993 ORSTOM Fonds Documentaire

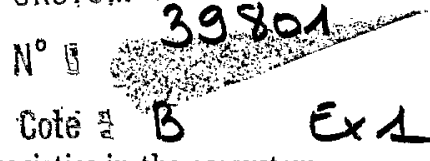

ABSTRACT

Cote 갈

Since a few years environmental studies have included human societies in the ecosystem in order to understand the interaction between the ecological and social dynamics and therefore there is a need to synthesize various scientific points of view. We have developed a simulator to represent both social, economic and ecological knowledge to contribute to a synthesis of the multidisciplinary knowledge of the Niger inland delta fishery.

In this paper we present the simulator, and, in order to give a general outline of its use we present different experimentations. The architecture of the simulator is based on Distributed Artificial Intelligence principle (multi-agents simulations, blackboard architecture, object oriented language). We simulate an aquatic ecosystem submitted to an increase of the fishing effort and compare the effect of different representation of fishing effort. As a result of the simulations, focus can be put on the relation between space sharing rules and the evolution of the ecological equilibrium. The simulator is considered as a discussion tool to lead to interdisciplinary meetings.

Keywards : Multi-agents, simulations, multidisciplinarity, fishery, decision-making process.

Nowadays, the economic and alimentary wellbeing of most societies is related a sustainable use of their natural environment. With the environmental changes $\mathrm{d}$ with increasing human needs, population growth and economic growth, this eraction is upset and therefore there is a greater need to understand the relation tween the organization of societies and the dynamics of environment, especially lewable resources. During the last twenty years this subject has become an portant field of the scientific research $[10,3,16]$. Thus, emphasis has heepgaid 
on the comparison between community based traditional resource management and scientific resource management systems coming from the industrial countries.

Although the value of simulating complex phenomena in order to come to a better understanding of their nature is well recognized, it is still rare for simulation to be used to understand social processes and their link with natural environment. We have developed a simulator based on Distributed Artificial Intelligence principle to represent both social and ecological features and to simulate their interactive dynamics. This research is conducted to contribute to a synthesis of the multidisciplinary knowledge on the Niger inland delta fishery. We present the simulator and some simple experimentations in order to give a general outline of its use.

\section{Modelling the Use of a Renewable Resource}

\subsection{Environmental Research: The Case of Niger Central Delta}

The scientific management of natural environments exploited by man has been for a long time directed towards the resource. In the field of aquatic resources many models $[9,17,4]$ have been developed to simulate the dynamics of fish populations. The aim of such models is to evaluate the influence of a mortality imposed by man and to determine the maximum sustainable yield in order to manage the exploitation. In these models man is considered as a disturbing element for the ecosystem.

Since a few years environmental studies have included man in the ecosystem. Thus, social sciences have been gradually involved in environmental research teams to study the economic and social processes in order to understand the action on the resource. Therefore, both economists, anthropologists and ecologists contribute to interdisciplinary studies on environment. Such is the case of the research team in the Niger Central Delta [18].

The Niger Central Delta is a flood plain situated in Mali covering approximatively 40000 square kilometers. The river whose water level varies considerably in the course of the year flows into a very flat zone. This hydrological situation creates a highly productive ecosystem. About 20000 households of fishermen exploit that ecosystem producing a quantity of fish which has decreased from 100000 tons to 50000 tons since the last twenty years. The population used to share the resource under the control of a system of access rules. This zone has been affected by different disturbing elements such as population growth and drought. Moreover, technical and legal changes over the last years have changed the management system. Since 1986 a multidisciplinary ORSTOM (Institut Français de Recherche Scientifique pour la Coopération en Développement) and IER (Institut d'Economie Rurale, Mali) research team has been trying to identify the causes of the decline of catches and to understand their relations. This team includes demographers, anthropologists economists and ecologists. The synthesis of knowledge acquired by different disciplines is difficult because each researcher has his own point of view on the reality, studies different objects, at various levels (Fig. 1) and

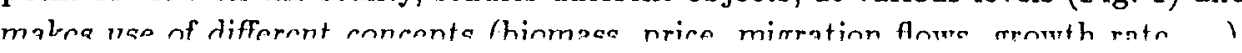

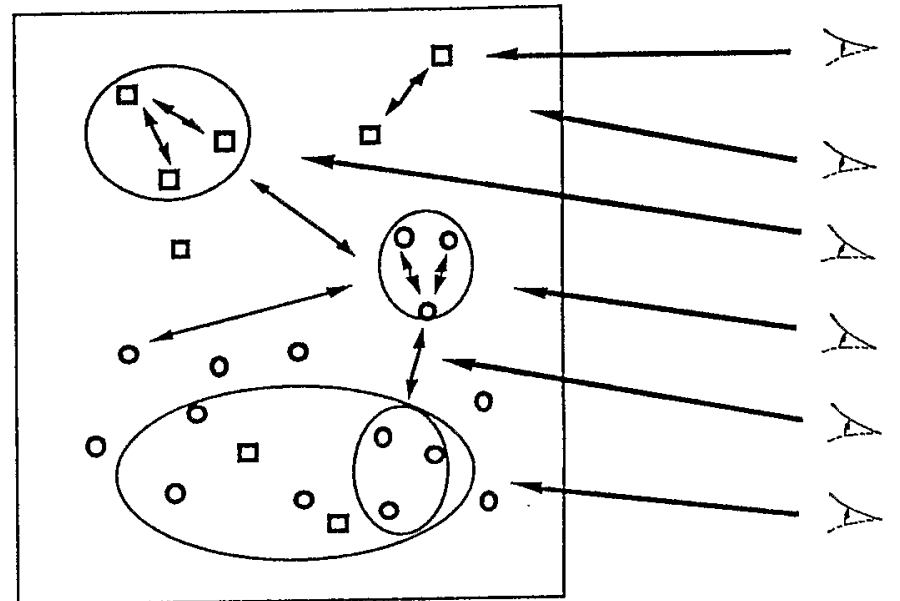

\section{Ecosystem $=$}

Set of interactive actors
Scientific knowledge = set of disciplinary points of view
Fig. 1. Model of an environmental scientific analysis.

\subsection{Modelling Interdisciplinary Knowledge}

Modelling is considered as a way to synthetize knowledge. Each discipline put forward its own model but the modelling of multidisciplinary knowledge must represent within the same framework various concepts and simulate the interaction between different dynamics. In the field of fishery science few models representing both human and ecological dynamics have been developed $[1,12]$. Therefore, there is a need to conceive and develop multidisciplinary models in the field of environmental studies. In the case of environmental studies a simulation model requires [15]:

- the dynamics of the natural environment,

- the processes of decision-making on cognition in general, which will include variables such as beliefs and attitudes.

Moreover we think that a simulator requires a structure to control the interaction of these processes and more precisely, the interaction of different scientific points of view on these processes. Different models are available: simulating an ecosystem implies making a choice among them. The simulator must underline this choice.

Rather than reproducing the reality, the aim of such modelling is to represent the available knowledge concerning this reality in order to help to make a synthesis of this knowledge. A simulator is considered as a discussion tool to lead to interdisciplinary meetings and to focus on interaction between society and resource. 


\subsection{A Method: Multi-agent Simulation}

The modelling of knowledge suggested here is based on the development and use of the principle of Distributed Artificial Intelligence and more precisely the multi-agent simulation. Multi-agent simulations are primarly used to report complex situations in which individuals have different behaviours and to analyse the global situation as emergent structures of the interactions [8]. Simulation can be achieved by transposing the population of a real ecosystem to its artificial counterpart. Each individual organism of the population is separately represented as a computing process, an agent. Thus, an artificial reality, an artificial world is built by representing different interacting agents.

"DAI agents are programmable on a computer, and are typically able (albeit in a very limited ways) to sense and react to their context, to communicate with one another, to accept and set themselves goals, to generate, reason about and execute plans of action in pursuit of their goals, and to maintain and update individual belief sets." [5]

Thus, we built a multi-agent simulator dedicated to the man-resource interaction and more precisely to the fishery of the Niger Central Delta.

\section{A Simulator}

We worked out a simulator to represent different types of knowledge and to simulate both fish population dynamics and the decision making process of the fishermen in order to understand better the relation between the resource and its use.

The simulator is separated in three parts (Fig. 2):

- an artificial world represented by different agents (fish, biotope, fisherman),

- different types of knowledge, points of view on the artificial world. Each discipline has models represented by a set of rules (knowledge sources, KS).

- a blackboard architecture manages the simulation. When an event occurs in the artificial world, the control structure is informed, activates the knowledge source concerned whose rules are applied, thus transforming the artificial world. These changes may constitute an event for another knowledge source, and so on ...

The simulator is written in Smalltalk language on Sun station.

\subsection{An Artificial World}

The artificial world is mainly represented by three agents, the biotope, the group of fish and the fisherman. We describe briefly the agents and their main fields (Fig. 3).

The biotope is a part of space. The spatial heterogeneity can be represented by a set of connected biotopes. Each week the water level changes and different biotopes may be connected or deconnected. For each biotope a curve describes the amount of food available for fish populations during the 52 weeks of the year. This curve represents the knowledge or hypothesis on the production of the lower trophic

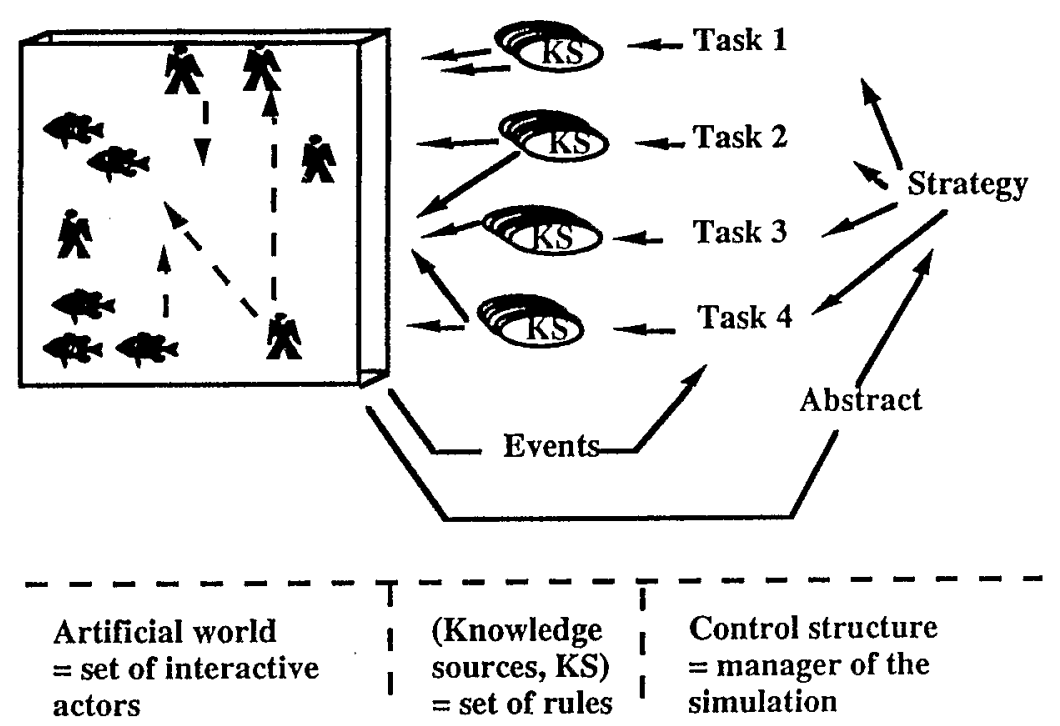

Fig. 2. The architecture of the simulator.

The group of fish is a part of a cohort (fishes born at the same place at the same moment) localized in a biotope. A group of fish is described by a weight distribution and various fields representing the strategy used to adapt to the environmental variability (size and number of eggs, migration process, diet). The group of fish may react to various stimuli.

The fisherman is represented by a lot of describing fields such as ethnic group, origin ... Otherwise, we defined:

- the equipment field includes a collection of objects corresponding to the different type of fishing gear the fisherman owns,

- the belief field is a data base where the fisherman records its past fishing results. Each result is indexed by both the biotope, the equipment and the season. This data base represents part of the fisherman's environmental perception.

- the activity field is a collection of all activities likely to be carried out. An activity is represented by a couple biotope-equipment, also called "technotope". Each activity is represented by the cost, the yield, the duration and a qualitative field in which a qualitative opinion on the activity $(+,-$, impossible, compulsory) can be recorded. These objects are the fisherman's environmental perception.

- the connexion field is a collection of other fishermen with whom interactions are possible (sharing of information, mimetic or repulsive attitude).

Thus, the capacities of the fisherman are more complex. His cognitive abilities are more important than the group of fish which is more reactive. He has an internal 
Object Biotope 1

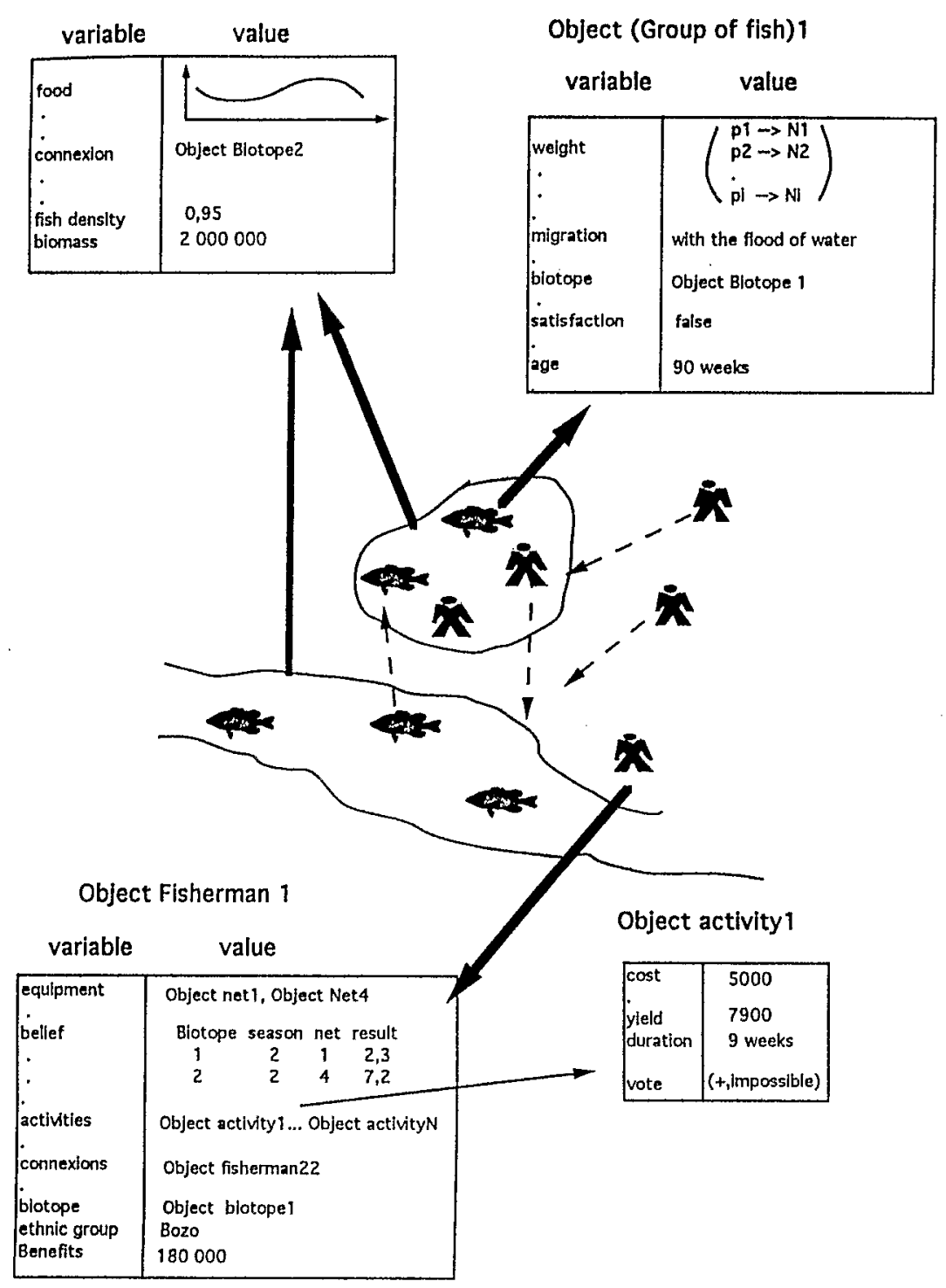

Fig. 3. The actors of the artificial world.

can accumulate experience to improve his perception.

These three agents, among some others like the market, constitute the artificial world, a transposition of the ecosystem. The functioning and dynamics of this ecosystem is observed and described by scientists. We report this knowledge inside , a set of rules named knowledge sources.

\subsection{Knowledge About the Artificial World}

The knowledge sources can be separated into four groups, called tasks: the first task concerns the hydro-ecological simulation and the following tasks are devoted to the decision making process.

The knowledge sources of the first task contain the ecological knowledge. During this stage, each biotope calculates a ratio $Q$ (available food/demanding biomass), then according to the biologists' knowledge [13,14,6,2] each group of fish grows, may migrate, is submitted to a mortality and may reproduce. These processes are called density-dependent, here they depend on the ratio $Q$.

For the purpose of representing decision making process, we remain close to a classical decision making modelling, divided into four phases: building upperception-selection-action.

During the building up stage the fishermen of the artificial world record all the activities likely to be carried out in the environmental conditions.

The perception task consists in getting information on each of the potential activities. Different knowledge sources interpret the natural and social environment and give information to the fisherman either in a quantitative transcription (cost or yield) or in a qualitative transcription (,+- , impossible, compulsory). For instance, in a top-down modelling an anthropological rule can be translated as:

If the fisherman belongs to the $X$ ethnic group,
en

In a bottom-up modelling a rule can be translated as:

If you are a mimetic fisherman and your neighbours adopt the activity

$X$, then adopt the activity $X$.

The selection stage consists in making a choice among the various possibilities offered. For this purpose different models are available. Some of them impose the decision, there is no choice, for others it comes to comparing the potential activities among them (selection of the most profitable activity, of the activity which got the most favourable opinions, the least unfavourable opinions, etc ...).

During the action stage, after determining its activity, the fisherman selects the corresponding equipement, goes to a biotope. There, his catch depends on the present amount of fish. The corresponding quantity is extracted from the different groups of fish and the fisherman records the result in its belief field, indexed by the biotope, the equipment and the season.

Therefore, the simulation enables to test different decision making models for fishermen. 


\section{Simulating a Fishery}

In order to give a general outline of the use of the simulator we propose different experimentations.

\subsection{A.ctors and Knowledge}

We worked out an artificial ecosystem composed of two biotopes, representing the river and the flood plain. The two biotopes have the same mean but the amplitude of the cycle is different: at the flood period the plain is a very rich biotope but at the dry season only small poor ponds remain. The step of the simulation is the week.

\subsubsection{The Resource}

The flood plain systems may contain more than one hundred species of fishes. Knowledge on the biological processes for each species is not available, but the biologists put forward a classification depending on the strategies adopted to face the environmental variability. These strategies concern mainly the season of the reproduction, the amount of eggs produced and the migration process.

We represented three species of fish: the first one $(A)$ is composed of small fishes, reproduces at the beginning of the flood period, produces a large number of eggs and migrates with the flood. The second one $(B)$ is larger, reproduces when the ecological conditions are favourable (food satisfaction), produces a smaller number of eggs and migrates when the conditions are unfavourable. The third species $(C)$ is a predator which reproduces at the beginning of the flood period and migrates when the conditions are unfavourable. According to the biologists we suppose that the three species may represent an artificial system whose ecological properties are similar to the flood plain systems. We simulate this system to reach an dynamic equilibrium between the three species. About one thousand groups of fish are represented.

\subsubsection{The Fishermen}

The fisherman can buy and use four different fishing gears. Each of them leads to a different caught depending on the fish density in the biotope. After some catches the gear must be changed. The fisherman has an initial amount of money, buys equipment and sell his production. Prices of equipment and fish are fixed. The fisherman can choose among eight activities (two biotopes $*$ four types of equipment). For each simulation step (a week) a pool of six fishing trips are recorded.

\subsection{The Simulations}

Once the ecological stability is obtained, the experimentation consists in simulating an increasing fishing effort on this artificial ecosystem. The aim is to represent both the demographic growth and the effect of the drought which reduced the size of the ecosystem. These processes lead to an increase of the fishing effort. This stress and the ecosystem response are called "fishing-up process" by the ecologists [19]. We consider three different experimentations to simulate it.

\subsubsection{The Society as a Simple Fishing Pressure}

The first experimentation imposes a fishing effort and so, given a capturability, a mortality vector (a probability to die) increasing from year to year. There is no fisherman agents, the only task is the ecological one. Each week we record for each species and each biotope the biomass, the abundance and the production (biomass produced). Moreover we record the captures separated into two groups: small fishes $(8-16 \mathrm{~cm})$ and large fishes (more than $16 \mathrm{~cm}$ ). Smaller fishes (less than $8 \mathrm{~cm}$ ) are not subrnitted to the exogenous mortality.

Figures 4(a), (b) and (c) show the ecosystem response. After having an increase the captures remain stable (Fig. 4(a)) during a long time although the fishing pressure increases: the exogenous mortality is balanced by the ecological production. During this first stage, the $B$ and $C$ species disappear (Fig. 4(b)) and the fish size decreases (Fig. 4(c)). Even though the fishing production is stable, the ecological structure evolves. At the end, the fishing mortality becomes so important that the fishery falls down.

This response, this pattern is validated by the ecological knowledge on flood plain fisheries [19]. The simulator enables us to observe the structure of the artificial ecosystem along the fishing-up process and to build indicators which can be used on the observed ecosystem.

\subsubsection{The Society as a Group of Actors}

Will the evolution of the capture be the same if the fishermen are able to adapt to their environment? In the next experimentations the fisherman is considered as an actor of the system. In order to simulate the fishing-up process the simulation begins with one fisherman and each year three fishermen are added. All tasks are considered in these simulations (ecological, building-up, perception, selection and action).

We have chosen to test two different models of decision making: a model with economic rules and a model with both economic and social rules.

\subsubsection{Actors with Economic Decision}

The perception rules only apply to calculating the cost of an activity (price of the equipment) and its yield (expected fishing result $*$ price of the fish). The selection stage consists of selecting the most profitable activity. During the action stage the fisherman extracts fishes from the biotope depending on the equipment and the density of fishes and his catch results are stored in the belief field. By this way he improves his environmental perception. 


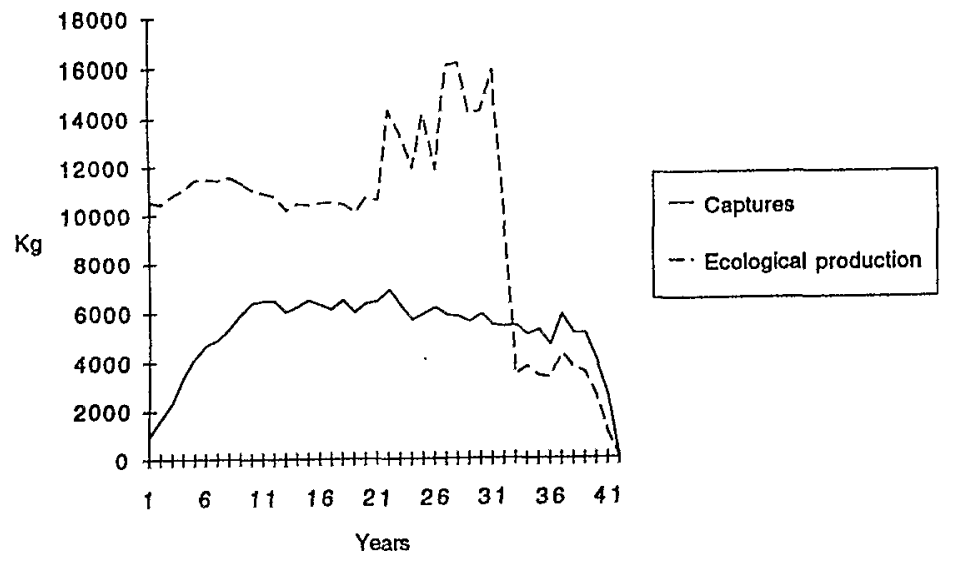

(a)

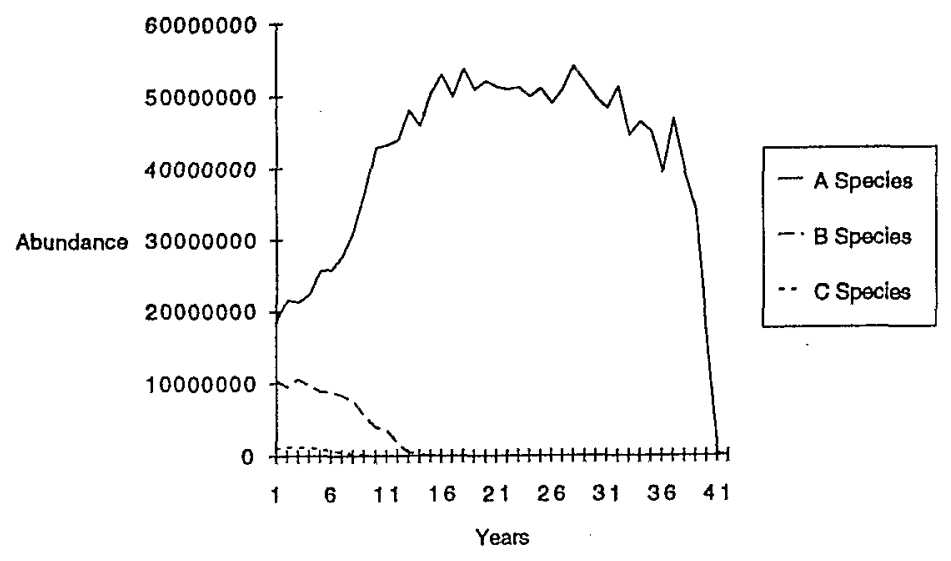

(b)

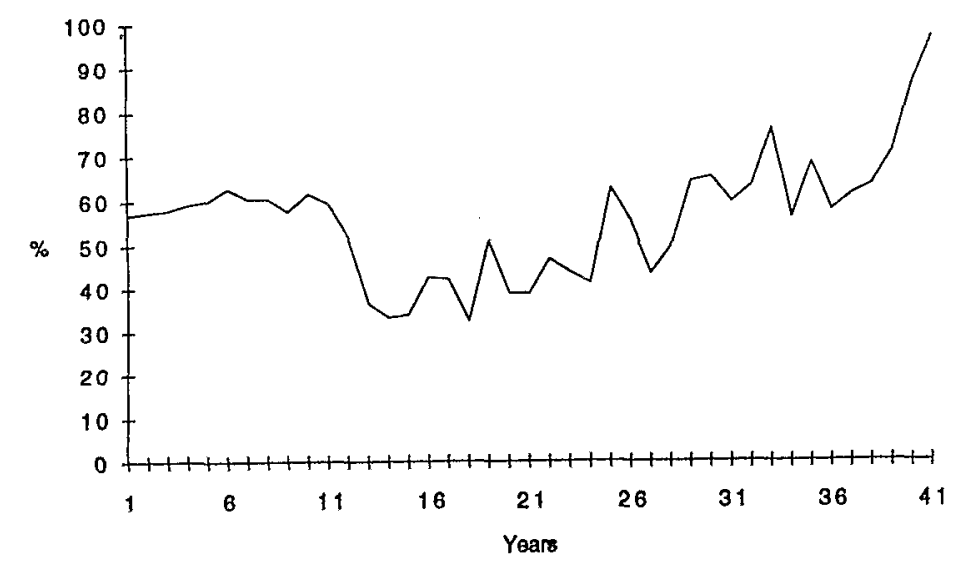

(c)

Fig. 4. Fishing up process with simple fishing pressure. (a) Evolution of the captures and the ecological production during the fishing up process. (b) Evolution of the abundance of the three species. (c) Evolution of the proportion of the small fishes $(8-16 \mathrm{~cm})$ in the captures.
The results are shown in Figs. 5(a), (b), (c) and (d): after an increase catches remain stable but the fishery never falls down (Fig. 5(a)). When the individual catches diminish the fisherman activity decreases. Some fishermen disappear and an equilibrium is reached: about 37 fishermen can exploit this resource (Fig. 5(b)). As a biological result we observe that during this stage, unlike the previous experiment, the abundance of the $A$ species diminish (Fig. $5(c))$. The $A$ species which reproduces at the flood period is very abundant during the decreasing and low water period. When the equilibrium is reached we observe that the fishermen's activity is concentrated at the decreasing period and at the end of the low period (Fig. 5(d)). Thus, the $A$ species is more affected than the $B$ species.

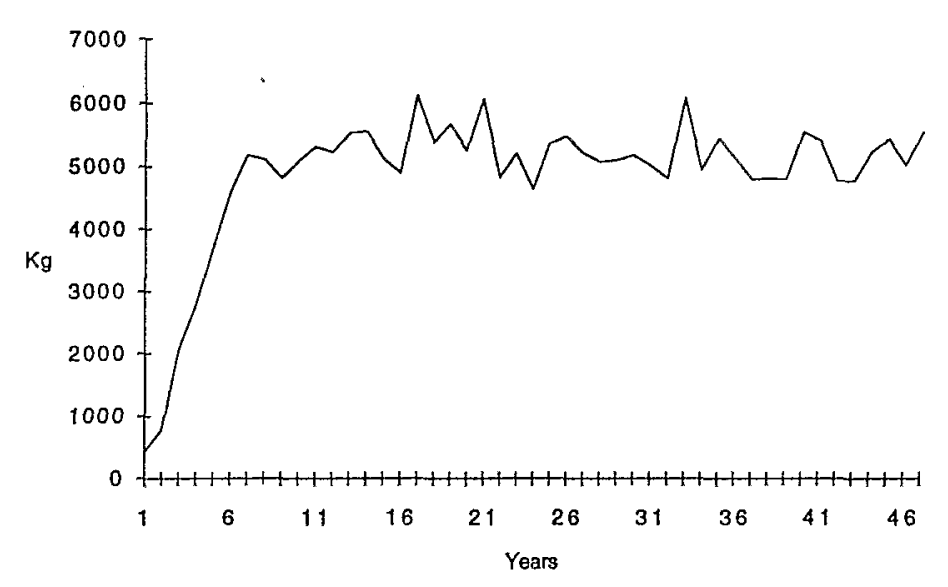

(a)

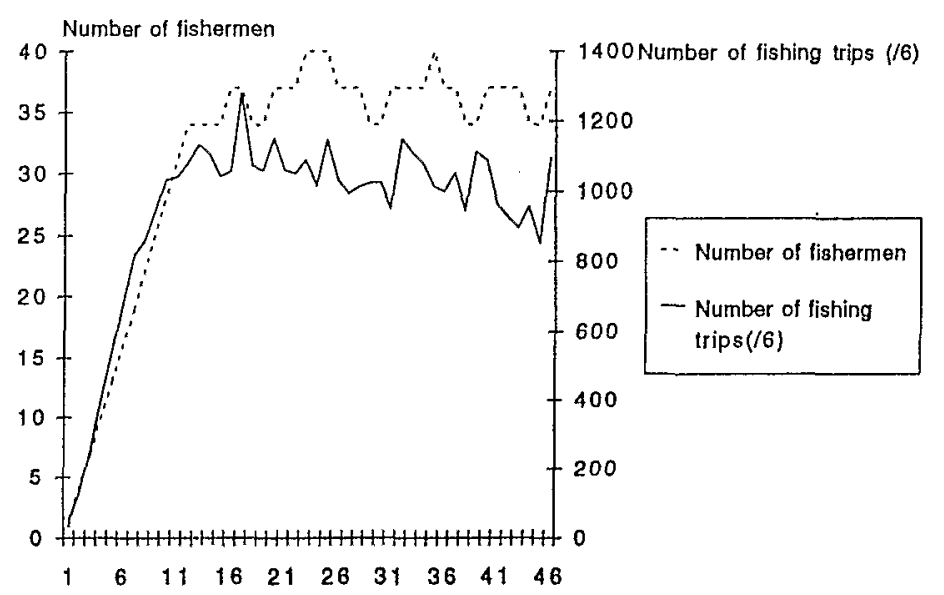

(b)

Fig. 5. Fishing up process with economic decision-making process. (a) Evolution of the captures. (b) Evolution of the number of active fishermen and the sum of fishing trips. (c) Evolution of the abundance of the three species. (d) Evolution of the annual activity. 


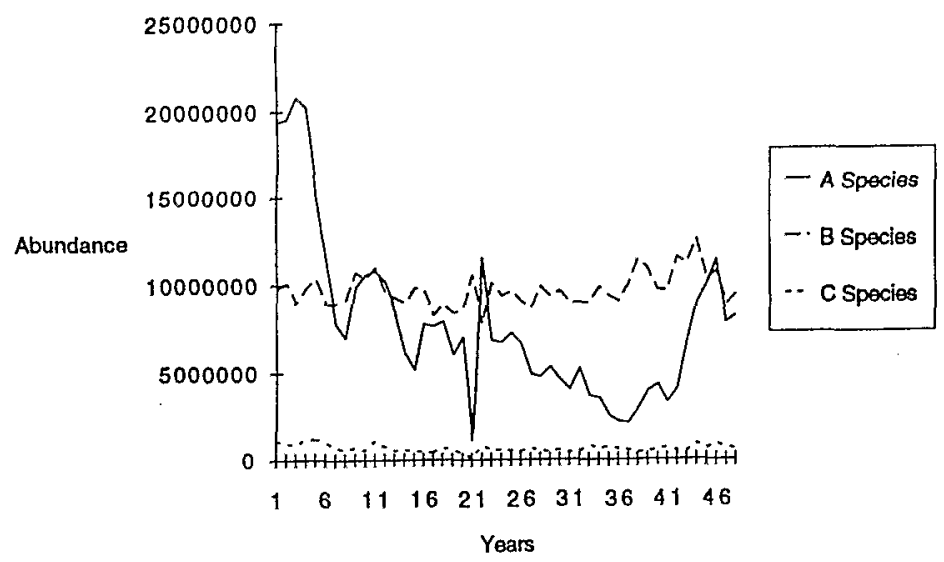

(c)

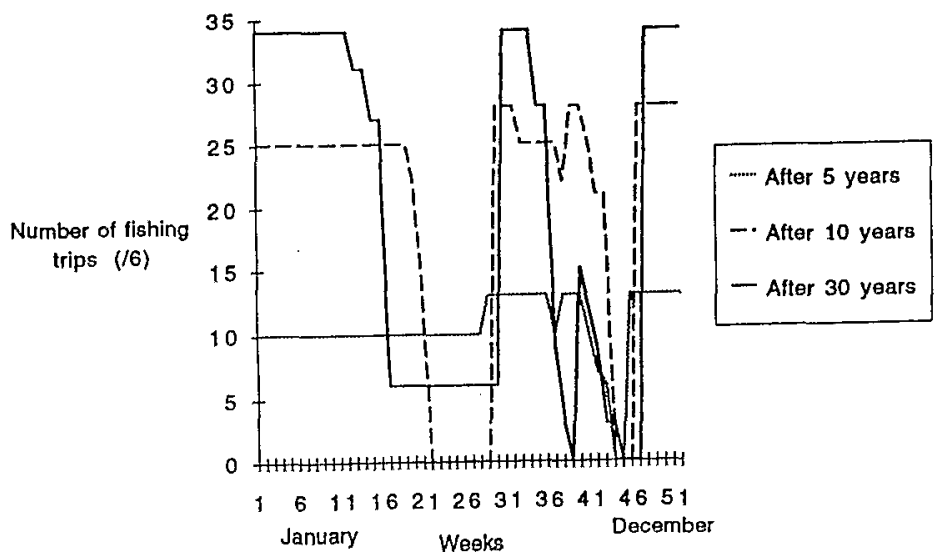

(d)

Fig. 5 Cont'd

\subsubsection{Actors With Both Economic and Social Decision}

The traditional society is structured and the use of the resource is regulated by a community-based knowledge which controls the access to the space $[7,11]$. The space is shared between different groups, ethnic groups, family, etc. This topdown control, from the group to the individual, partly imposes the activity of the fishermen.

To give an example we simulate the following society: the population is divided into two groups, one of this group has no access to the plain biotope, the other one has no access to the river biotope at the low period. The structure of the simulator is the same but we reproduce these rules in a knowledge source of the perception stage. When a fisherman is generated his ethnic group is randomly $(50 \%-50 \%)$ chosen.

We observe that the catch results (Fig. 6(a)) are not affected by this social structure. Although the size of the group increases up to 45 fishermen (Fig. 6(b)), the size of the society reaches the same attractor (about 37 fishermen). The main difference lies in the fish population dynamics: after a decline the abundance of the $A$ species grows and it recovers its initial level (Fig. 6(c)).

\subsection{Interpretation of the Results}

The artificial universe described is very far from the ecosystem of the Niger Central Delta: we represent only three species of fishes and a very schematic communitybased system. The purpose of this modelling is not to validate very precisely our 1 results. As a result of our experiment, focusing on the man-resources interactions we can propose a discussion on the following remarks:

- the rules of space sharing do not change the quantitative equilibrium between the society and the resource,

- these rules may change the ecological equilibrium between the differents species favourising some fish adaptative strategies,

- there is an important variability of the fish population dynamics while the dynamics of the fishermen society seems more stable.

This debate interests economists, anthropologists, ecologists and decision makers and may help to an interdisciplinary synthesis of the knowledge. Considering the evolution of the artificial universe, this discussion can be supported by the observation on the real ecosystem of various indicators such as the evolution of the biomass captured, and the evolution of the composition and the size of the captures, and the evolution of the spatio-temporal activity.

Otherwise, this simulation can be rejected by members of the team who underline some important points which have not been taken into acount. This is an information for the rest of the team and may be the subject of a new experimentation. It allows us to focus on some parts of the knowledge which change the understanding of the global ecosystem. The modelling tools chosen and developed allow quick changes to test different hypothesis.

\section{Conclusion}

The multidisciplinary team of the Niger Central Delta has achieved the stage of knowledge acquisition. Nowadays its task is to conduct a synthesis of this heterogeneous knowledge. After disciplinary surveys and interviews of the last years one important purpose of the synthesis is to define some indicators of the interactions between the society and the resource in order to propose an interdisciplinary observation of the ecosystem.

We have developed a multi-agent simulator which includes both fish population dynamics and decision making process for a better understanding of the interactions 


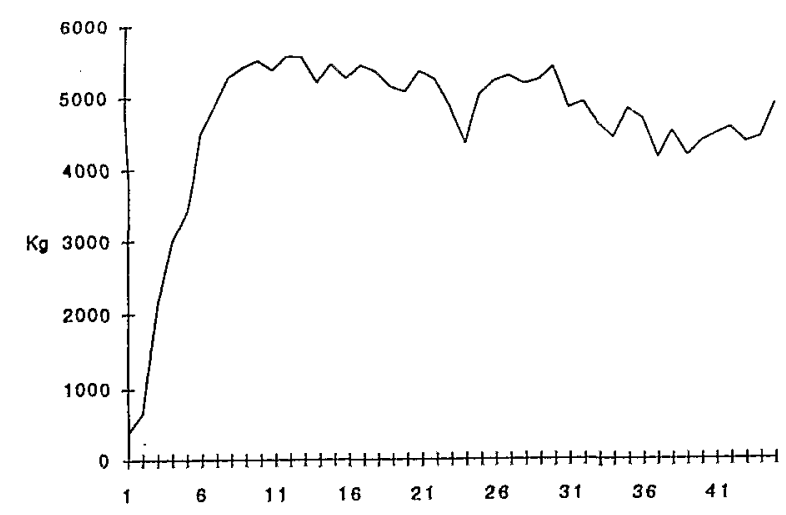

(a)

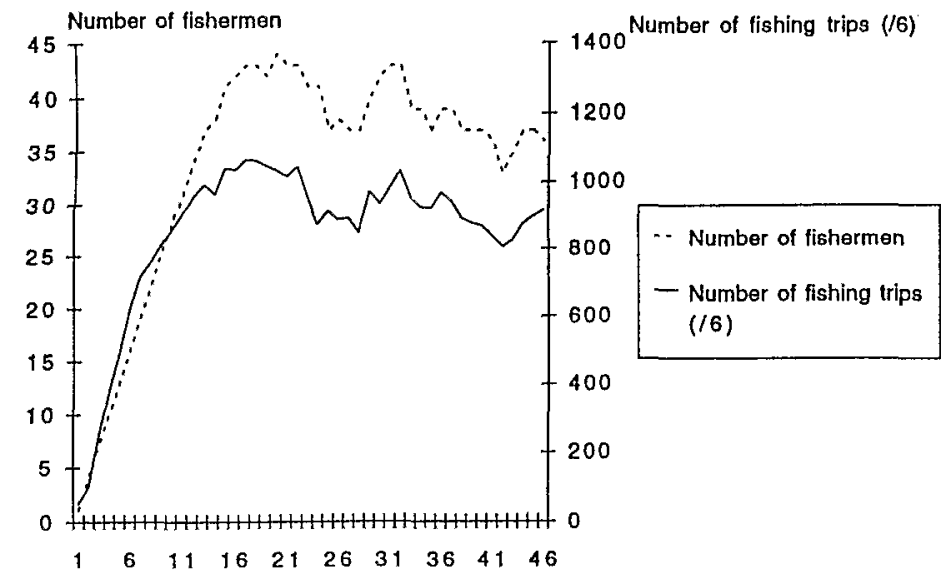

(b)

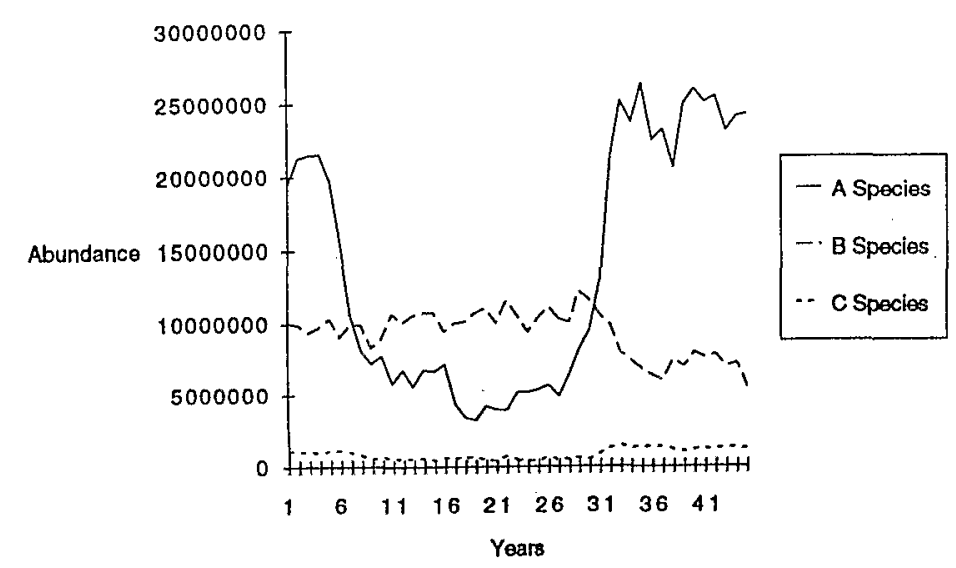

(c) between the fishermen and the resource. Rather than proposing a global model of the whole environmental knowledge which should predict the evolution of the ecosystem, this tool is used to test different hypotheses, to propose subjects of interdisciplinary discussions. We build artificial worlds on which we can define indicators of the social and ecological interactions and then observe this indicators on the real ecosystem.

\section{References}

[1] Allen P. M. and McGalde J. M., Dynamics of discovery and exploitation: the Scotian shelf Fisheries. Can. J. of Fish. and Aquat. Science 43, No. 6 (1986).

[2] Benech. V. et Quensière J., Dynamique des peuplements ichtyologiques de la région du Lac Tchad (1966 - 1978). Influence de la sécheresse sahélienne. Thèse Doct. d'Etat de l'Université des Sciences et Techniques de Lille (1987).

[3] Berkes F., Feeny D., MacKay B. J., Acheson J. M., The benefits of the Commons, Nature 340 (1989).

[4] Beverton R. J. H, Holt S. S, On the dynamics of exploited fish populations. U.K. Min Agric Fish Food, Fishery investigations (Ser. 2) 19 (1966) pp. 533.

[5] Doran J., DAI and emergent social complexity (1991). Paper presented at conf. on Dynamical Description and Human Systems, Cambridge (Dec. 1992)

[6] Durand J. R., Biologie et dynamique des populations d'Alestes baremoze (Pisces, Characidae) du Bassin Tchadien. ORSTOM ed. coll. Trav. et Doc. Paris 98 (1978) pp. 322.

[7] Fay C., Sacrifices, prix du sang, eaux du mattre: fondation des territoires de pêche dans le Delta Central du NIger (Mali). Cahier des Sciences humaines, ORSTOM, (1990).

[8] Ferber, Objets et agents: une étude des structures de représentation et de communications en Intelligence Artificielle. Thèse d'état, Paris 6 (1989).

[9] Graham G., Modern theory of exploiting a fishery and application to NorthSea trawling. J. Cons. perm. int. Explor. Mer, 10, No. 2 (1935) pp. 264-274.

[10] Hardin G., The Tragedy of the Commons, Science 162, (1968) pp. 1243-1246.

[11] Kassibo B., La dynamique de la pêche dans le delta intérieur du fleu ve Niger (Mali) de la période pré-coloniale á nos jours. In Boucle du Niger, approches multi-disciplinaires, ed. by Kawada (1988).

[12] Laloe F. and Samba A., La pêche artisanale au Senegal: ressource et stratégies de pêche. These Universite Paris Sud, (1992).

[13] Lauzanne L., Les habitudes alimentaires des poissons d'eau douce Africains. pp. 221242. In Biologie et Ecologie des poissons d'eau douce Africains, ed. by Lévêque and Bruton et Ssentongo (1988). Editions de l'ORSTOM. pp. 508 Paris.

[14] Merona (de) B. and T. Hecht et J. Moreau, Croissance des poissons d'eau douce Africains, pp. 191-219 in Biologie et Ecologie des Poissons d'eau douce Africains, ed. by Lévêque, Bruton et Ssentongo (1988). Editions de l'ORSTOM. pp. 508 Paris.

[15] Mithen S., Simulating Prehistoric Hunther-gatherer Societies. Proc. of Simulating Societies Symp., Univ. of Surrey, Guildford UK (1993).

[16] Ostrom E., Governing the Commons, the Evolution of Institutions for Collective Actions, Cambridge Univ. Press (1990).

[17] Pella J. J, Tomlinson P. K., A general stock production model. Bull. IATTC 13 (1969), pp. 419-496.

[18] Quensiere J., Etudes halieutiques du DCN, Enquête statistique auprès des pêcheurs, premiers résultats, ORSTOM-INRZFH, Bamako (1988).
Fig. 6. Fishing up process with socio-economic decision-making process. (a) Evolution of the captures. (b) Evolution of the number of active fishermen and the sum of fishing trips. (c) Evolution of the abundance of the three species. 